\title{
New records of Hypoxylon (Ascomycota, Hypoxylaceae) for the Argentine Yungas
}

\author{
Sofía M. DIAZ ${ }^{1}$, Esteban B. SIR ${ }^{*}$, Eric KUHNERT ${ }^{3}$ \& Adriana I. HLADKI ${ }^{1}$ \\ ${ }^{1}$ Fundación Miguel Lillo, Laboratorio Criptogámico, Miguel Lillo 251, San Miguel de Tucumán 4000, Tucumán, \\ Argentina. ${ }^{2}$ Fundación Miguel Lillo, CONICET, Laboratorio Criptogámico. ${ }^{3}$ Institute for Organic Chemistry, \\ BMWZ, Leibniz Universität Hannover, Schneiderberg 38, 30167 Hannover, Germany. *Corresponding author: \\ sirestebanbenjamin@gmail.com
}

\begin{abstract}
Hypoxylon aeruginosum var. aeruginosum, $H$. fendleri and $H$. undulatum collected in the subtropical montane forest from northwest Argentina are reported for the first time for the Southern Cone. We describe and analyze their teleomorph and anamorph, and provide photographs and drawings of the most relevant structures. Moreover, a key to Hypoxylon species so far known from Argentina is given.
\end{abstract}

Key words: Neotropics, Mycobiota, Xylariales.

Resumen: Nuevos registros de Hypoxylon (Ascomycota, Hypoxylaceae) para Las Yungas Argentinas. Como resultado del estudio de especímenes coleccionados en el bosque montano del Noroeste Argentino, se citan por primera vez para el Cono Sur a Hypoxylon aeruginosum var. aeruginosum, $H$. fendleri y H. undulatum. Se describen y analizan los teleomorfos y anamorfos de esas especies, aportando fotografías y dibujos de las estructuras más relevantes. Además, se proporciona una clave para identificar las especies de Hypoxylon hasta ahora conocidas en Argentina.

Palabras clave: Neotrópico, Micobiota, Xylariales.

\section{INTRODUCTION}

Hypoxylon Bull. is the largest and most complex genus of the family Hypoxylaceae (Wendt et al., 2018). The genus includes species with unipartite hemispherical to effused-pulvinate stromata with colored surface and homogeneous waxy to fibrous tissue bellow perithecial layer; and a nodulisporium-like anamorph, but with variations in the branching patterns of the conidiophores (Daranagama et al., 2018; Ju \& Rogers, 1996; Wendt et al., 2018). Their stromata release diverse pigments in contact with $\mathrm{KOH}$ solution. These pigments are secondary metabolites deposited as colored granules below the stromatal surface and surrounding the perithecia, which frequently can possess species-specific chemical entities useful to discriminate Hypoxylon species (Hellwig et al., 2005; Kuhnert et al., 2014ab; Stadler et al., 2008).

Members of the genus are recognized as saprobes or as facultative parasites when found on wood, but can also be isolated as part of the en- dophytic community in most of the forest trees (Kuhnert et al., 2014a). The majority of species has been reported from warmer climates especially the Tropics. This however could be the result of less extensive sampling in subtropical or temperate areas of the world (Fournier et al., 2015).

Since the beginning of the century, several surveys on the xylariaceous diversity have been carried out in the Argentine Yungas, the southernmost subtropical montane forest of the Neotropics (Hladki, 2007; Kuhnert et al., 2015, 2017; Sir et al., 2012abc, 2013, 2015, 2016ab, 2018; Sir \& Hladki, 2014). These mycological trips showed that the genus Hypoxylon is a remarkable, yet poorly documented component of the mycobiota of this ecosystem (Sir et al., 2012a). Hladki \& Romero (2009ab) and Catania \& Romero (2010) published the first reports of Hypoxylon species from the Argentine northwest, recording less than ten species. In one of our previous studies, we already increased the knowledge about the diversity of the genus (Sir et 
al., 2016). In this context we proposed three new species: $H$. calileguense Sir, Kuhnert, Hladki \& A.I. Romero, H. lilloi Sir, Lamb. \& Kuhnert and H. spegazzinianum Sir, Kuhnert, Hladki \& A.I. Romero; and recognized eight new records for Argentina: $H$. carneum Petch, $H$. chionostomum Speg, H. flavoargillaceum J. H. Mill., H. griseobrunneum (B.S. Mehrotra) J. Fourn., Kuhnert \& M. Stadler, H. haematostroma Mont., H. investiens (Schwein.) M.A. Curtis. H. lividipigmentum F. San Martín, Y. M. Ju \& J. D. Rogers, and H. umbilicatum Speg.

Here we report, three new species records of Hypoxylon for the Southern Cone of South America, collected in the Argentine Yungas. Also, we provide an emended taxonomic key for Hypoxylon species known from Argentina.

\section{MATERIALS AND METHODS}

Fungal collections were obtained between 2011 and 2015 at the Parque Nacional Calilegua and Reserva Provincial Las Lancitas from Jujuy province, Reserva provincial de Flora y Fauna Acambuco and Parque Nacional el Rey from Salta province, and Parque Sierra de San Javier from Tucuman province.

The materials were studied and isolated according to Sir et al. (2016). The color of stromata and extractable pigments are described following the color chart of Rayner (1970). The perispore was analysed under field-emission scanning electron microscope (SEM-Zeiss, Supra 55vp) in the Centro Integral de Microscopía Electrónica (CIME, CONICET-UNT). The reference collections were deposited in the LIL herbarium. Additional specimens examined were obtained from LIP and $\mathrm{K}$ herbaria (acronyms are from Index Herbariorum, http://sciweb.nybg.org/ science2/IndexHerbariorum.asp). The author names of the fungal species were taken from Index Fungorum (http://www.indexfungorum. org/).

\section{RESULTS}

\section{Taxonomic part}

Hypoxylon aeruginosum J.H. Mill., var. aeruginosum Mycologia, 25 (4): 321(1933). Figs. 1 and $4 \mathrm{a}$

Stromata effused-pulvinate; $10-25 \mathrm{~mm}$ long $\times$ 5-15 mm broad $\times 0.4-6 \mathrm{~mm}$ thick; with inconspicuous perithecial mounds to plane; surface
Verdigris (74) to Cyan Blue (26) with Brick (59) margin, pruinose; black granules immediately beneath the surface and between perithecia, pale blue and pale green in water; with $\mathrm{KOH}$ extractable pigments Umber (9) with Pale Vinaceous (85) tones; tissue bellow the perithecial layer inconspicuous, black. Perithecia obovoid to spherical $0.25-0.4 \mathrm{~mm}$ high $\times 0.1-0.2 \mathrm{~mm}$ diam., ostioles umbilicate. Asci cylindrical, 8-spored, 118-154 $\mu \mathrm{m}$ total length, the spore-bearing parts $68-75 \times 6.8-8 \mu \mathrm{m}$ and stipes $49-80 \mu \mathrm{m}$ long, with amyloid apical apparatus, discoid, 0.5$0.7 \mu \mathrm{m}$ high $\times 2-2.5 \mu \mathrm{m}$ broad. Ascospores light brown to brown, unicellular, ellipsoid, nearly equilateral, with broadly to less frequently narrowly rounded ends, $8-11.3(11.5) \times 4.4-6 \mu \mathrm{m}$ $(\mathrm{N}=60, \mathrm{Me}=10.1 \times 5.5 \mu \mathrm{m})$, with straight germ slit less than to nearly spore-length; perispore indehiscent in $10 \% \mathrm{KOH}$; epispore smooth under LM and SEM. Conidiogenous structure with virgariella-like branching patterns. Conidiophores hyaline, smooth. Conidiogenous cells hyaline, smooth, 15-27(38.5) $\times 2.3-2.9 \mu \mathrm{m}$. Conidia ellipsoid, hyaline, smooth, $4-6.4 \times 2.9-3.8 \mu \mathrm{m}$.

Culture: not obtained.

Secondary metabolites: derivatives of lepraric acid (Læssøe et al., 2010).

Specimens examined: ARGENTINA. Tucumán, depto. Tafí Viejo, Parque Sierra de San Javier, la Cascada, 6/5/2013, Sir \& Hladki 410 (LIL). FRENCH GUIANA: Sinnamary, Paracou, edge of parking area of CIRAD field station, on a corticated branch, possibly on old remnants of a Corticiaceae, 26/6/2012, leg. J. Fournier, GYJF 12236 (LIP, epitype).

Discussion: Hypoxylon aeruginosum is a species that was unknown from subtropical regions of the American continent, being previously recorded only from sites of the American tropical zone, i.e. Ecuador, French Guiana, Guadeloupe, Guyana, Martinique and Mexico (Fournier et al., 2015; Fournier \& Lechat, 2015). This taxon is distinct from other Hypoxylon by its blue effused-pulvinate stromata and nearly equilateral ascospores which measure less than $11.5 \mu \mathrm{m}$ (Ju \& Rogers, 1996). The anamorph of this species is characterized and illustrated for first time herein.

In our collection a part of the specimen was found on top of another Hypoxylon sp. This phenomenon was also observed by Læssøe et al. (2010), who suggested a fungicolous life style. 

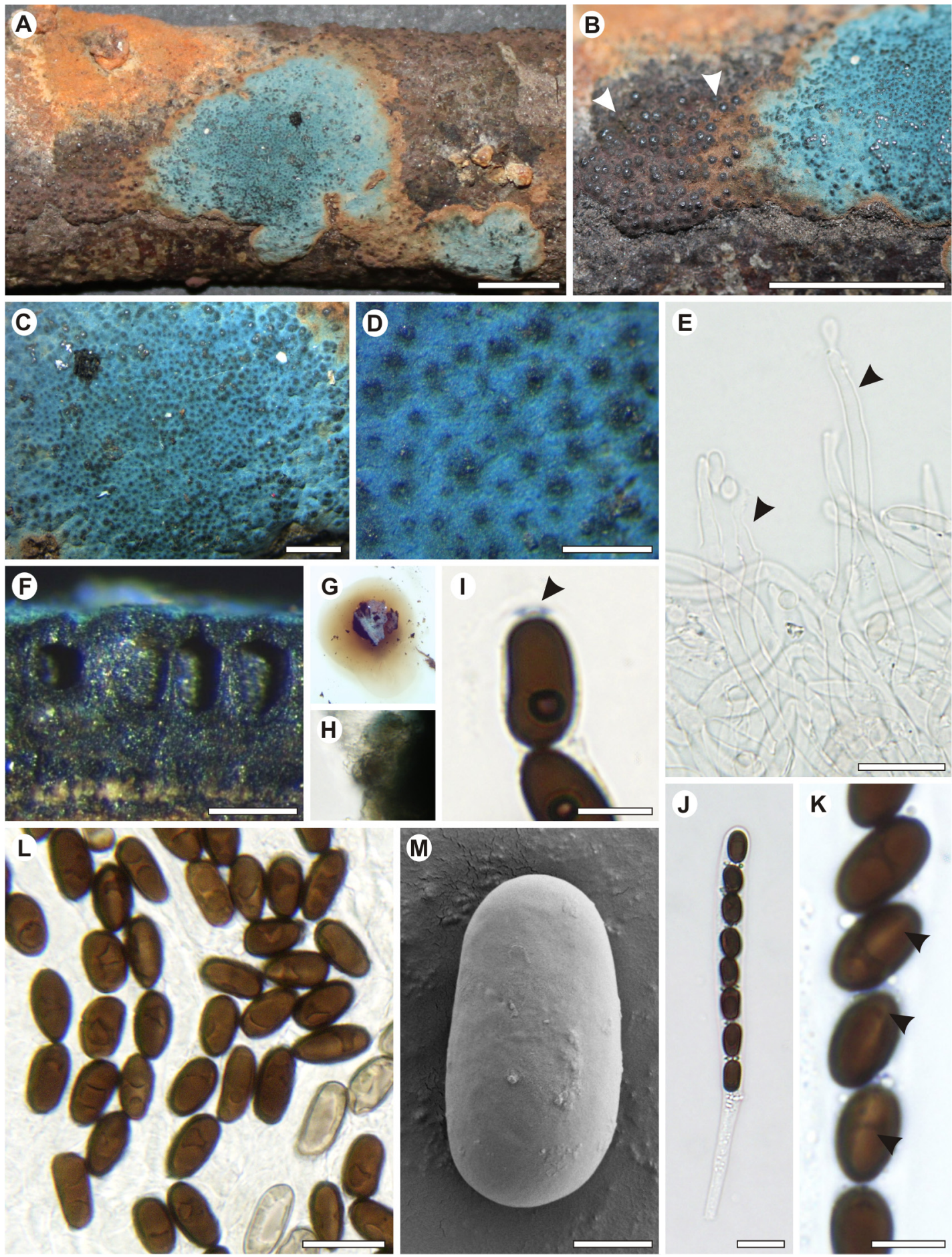

Fig. 1. Hypoxylon aeruginosum (Sir \& Hladki 410-LIL). A: stromata on substrate, B: detail of stroma on top of Hypoxylon sp. (arrows). C and D: details of stromatal surface showing ostioles. E: portion of anamorph showing conidiogenous cells (arrows). F: stroma in section showing the perithecia. G: KOH-extractable pigments, H: stromatal granules in water. I: ascal apical apparati in Melzer's reagent. J: mature ascus. K: ascospores in $\mathrm{KOH}$ solution showing germ slit (arrows). L: ascospores in water. M: ascospores view under SEM showing smooth epispore. Scale bars. A, B: $5 \mathrm{~mm}$. C: $1 \mathrm{~mm}$. D, F: $0.3 \mathrm{~mm}$. E, J, L: $10 \mu \mathrm{m}$. I, K: $5 \mu \mathrm{m}$. M: $2 \mu \mathrm{m}$. 
Hypoxylon fendleri Berk. ex Cooke, Grevillea 11: 132. 1883. Figs. 2 and 4b.

Stromata effused-pulvinate; $5-40 \mathrm{~mm}$ long $\times$ 3-20 mm broad $\times 0.7-1 \mathrm{~mm}$ thick; with conspicuous to inconspicuous perithecial mounds, in some case with wrinkled surface; surface Brown Vinaceous (84) with orange tones, pruinose; orange granules immediately beneath the surface and between perithecia, orange in water; with $\mathrm{KOH}$-extractable pigments Orange (7); tissue bellow the perithecial layer inconspicuous, black. Perithecia obovoid $0.4-0.6 \mathrm{~mm}$ high $\times 0.3-0.5$ $\mathrm{mm}$ diam., ostioles umbilicate. Asci cylindrical, 8-spored, 85-160 $\mu \mathrm{m}$ total length, the spore-bearing parts $70-80 \times 6-7.88 \mu \mathrm{m}$ and stipes $45-80$ $\mu \mathrm{m}$ long, with amyloid apical apparatus, discoid, 0.7-1.4 $\mu \mathrm{m}$ high $\times 2-2.7 \mu \mathrm{m}$ broad. Ascospores brown to dark brown, ellipsoid-inequilateral, with narrow rounded ends, (8.4)9.3-11.7(12.4) $\times(4.6) 4.8-5.9(6.6) \mu \mathrm{m}(\mathrm{N}=60, \mathrm{Me}=10.7 \times 5.4$ $\mu \mathrm{m})$, with sigmoid germ slit spore-length on the convex side; perispore dehiscent in $10 \% \mathrm{KOH}$, smooth to faintly striated under LM, striated under SEM; epispore smooth. Conidiogenous structure with virgariella-like and nodulisporium-like branching patterns. Conidiogenous cells hyaline, smooth to slightly roughened, $15-25 \times 2.1-3.4$ $\mu \mathrm{m}$. Conidia ellipsoid, hyaline, smooth, 5.0-5.9 $\times 3.1-3.9 \mu \mathrm{m}$.

Culture: for description see $\mathrm{Ju} \&$ Rogers (1996).

Secondary metabolites: mitorubrin, mitorubrinol, mitorubrinol acetate, orsellinic acid and BNT (Stadler et al., 2008).

Specimens examined: ARGENTINA, Jujuy, dpto. Santa Bárbara, Reserva Provincial Las Lancitas, 13/5/2012, Sir \& Hladki 248 (LIL). Salta, La Candelaria, El Jardín, 3/5/2013, Sir \& Hladki 387 (LIL). Dpto. Gral. José de San Martín, Reserva de Flora y Fauna Acambuco, 22/4/2014, Sir \& Hladki 505 (LIL); road to Reserva de Flora y Fauna Acambuco, 23/4/2014, Sir \& Hladki 574 (LIL); 21/5/2015, Sir \& Hladki 950 (LIL). Dpto. Anta, Parque Nacional El Rey, 29/4/2014, Sir \& Hladki 712, 720 (LIL); 28/5/2015, Sir \& Hladki 887 (LIL). VENEZUELA: 261, corticated wood (K, holotype).

Discussion: Hypoxylon fendleri is a very common fungus in the tropical regions of the world (Fournier et al., 2015); this is the first record of the species for a subtropical area of South America. The taxon can be identified by its vinaceous stromatal surface, orange granules, orange extractable pigments, ascospores with sigmoid germ slit and nodulisporium-like anamorph (Ju \& Rogers, 1996). The characteristics of the cultures obtained from Argentinean material were in accordance with previous descriptions for species (Ju \& Rogers, 1996).

\section{Hypoxylon undulatum Y.M. Ju, J.D. Rogers \&} Læssøe, Mycol. Mem. 20: 199 (1996).

Figs. 3 and $4 \mathrm{c}$.

Stromata effused-pulvinate; 10-25 mm long $\times$ 5-15 mm broad, 0.4-1 mm thick; with conspicuous to very conspicuous perithecial mounds, in some case approaching to rosellinoid; surface Brown Vinaceous (84) to Fuscous (103), pruinose; dull rusty brown granules immediately beneath the surface and between perithecia, reddish brown in water; without apparent $\mathrm{KOH}$-extractable pigments; tissue bellow the perithecial layer inconspicuous, black. Perithecia spherical to spherical compressed 0.2-0.3 mm diam, ostioles umbilicate, opening at the centre of a raised disc, $0.1-0.13 \mathrm{~mm}$ diam. Asci cylindrical, 8-spored, 89-117 $\mu \mathrm{m}$ total length, the spore-bearing parts $64-77 \times 5-7.7$ $\mu \mathrm{m}$ and stipes $20-40 \mu \mathrm{m}$ long, with amyloid apical apparatus, discoid, $1 \mu \mathrm{m}$ high $\times 1.5-1.8$ $\mu \mathrm{m}$ broad. Ascospores brown to dark brown, ellipsoid-inequilateral, with narrow rounded ends, (9.1)9.6-11.0(11.6) $\times$ (3.5)3.9-4.8(5.1) $\mu \mathrm{m}(\mathrm{N}=60, \mathrm{Me}=10.3 \times 4.2 \mu \mathrm{m})$, with straight germ slit spore-length on the convex side; perispore dehiscent in $10 \% \mathrm{KOH}$, smooth to faintly striated under LM, faintly striated under SEM; epispore smooth. Conidiogenous structure with virgariella-like and nodulisporium-like branching patterns. Conidiophores hyaline, smooth to slightly roughened, Conidiogenous cells hyaline, smooth to slightly roughened, 10.4-23 × 2-2.8 $\mu \mathrm{m}$. Conidia ellipsoid, hyaline, smooth, 3.5-5 (6.5) $\times 2.2-3.5 \mu \mathrm{m}$.

Culture: for description see Ju \& Rogers (1996).

Secondary metabolites: unknown.

Specimens examined: Argentina. Jujuy, Ledesma, Parque Nacional Calilegua, 12/12/2015, Sir \& Hladki 997 (LIL). Gral. José de San Martín, road to Reserva de Flora y Fauna Acambuco, 21/5/2015, Sir \& Hladki 849 (LIL).

Discussion: Hypoxylon undulatum was only known by its type material from Saint John (U. S. Virgins Island). This species is characterized by having effused-pulvinate stromata, fuscous surface with strongly exposed perithecial mounds, ostioles with a raised disc and by lacking apparent 

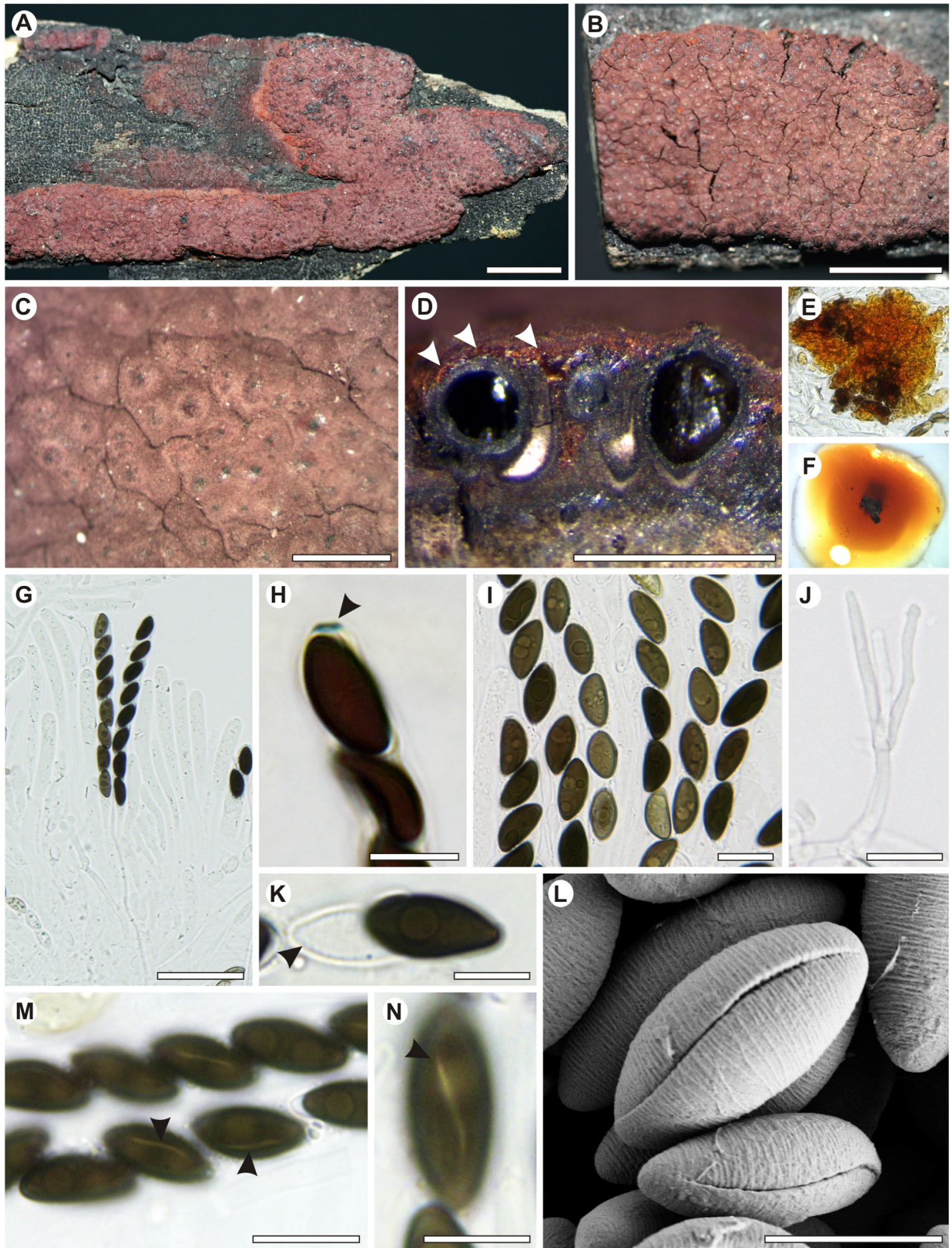

Fig. 2. Hypoxylon fendleri (Sir \& Hladki 574-LIL). A and B: stromatal habit. C: stromatal surface. D: stroma in section showing perithecia and granules (arrows). E: stromatal granules in water. F: extractable pigments. G: immature and mature asci. H: ascal apical apparati in Melzer's reagent. I: immature and mature ascospores in water. J: branching of anamorph. $\mathrm{K}$ : ascospores in $\mathrm{KOH}$ solution showing dehiscent perispore. L: ascospores view under SEM showing striated perispore. M and N: ascospores in KOH solution showing germ slit (arrows). Scale bars. A, B: $5 \mathrm{~mm}$. C, D: $1 \mathrm{~mm}$. G: $20 \mu \mathrm{m}$. H, I, J, M: $10 \mu \mathrm{m}$. K, L, N: $5 \mu \mathrm{m}$. 

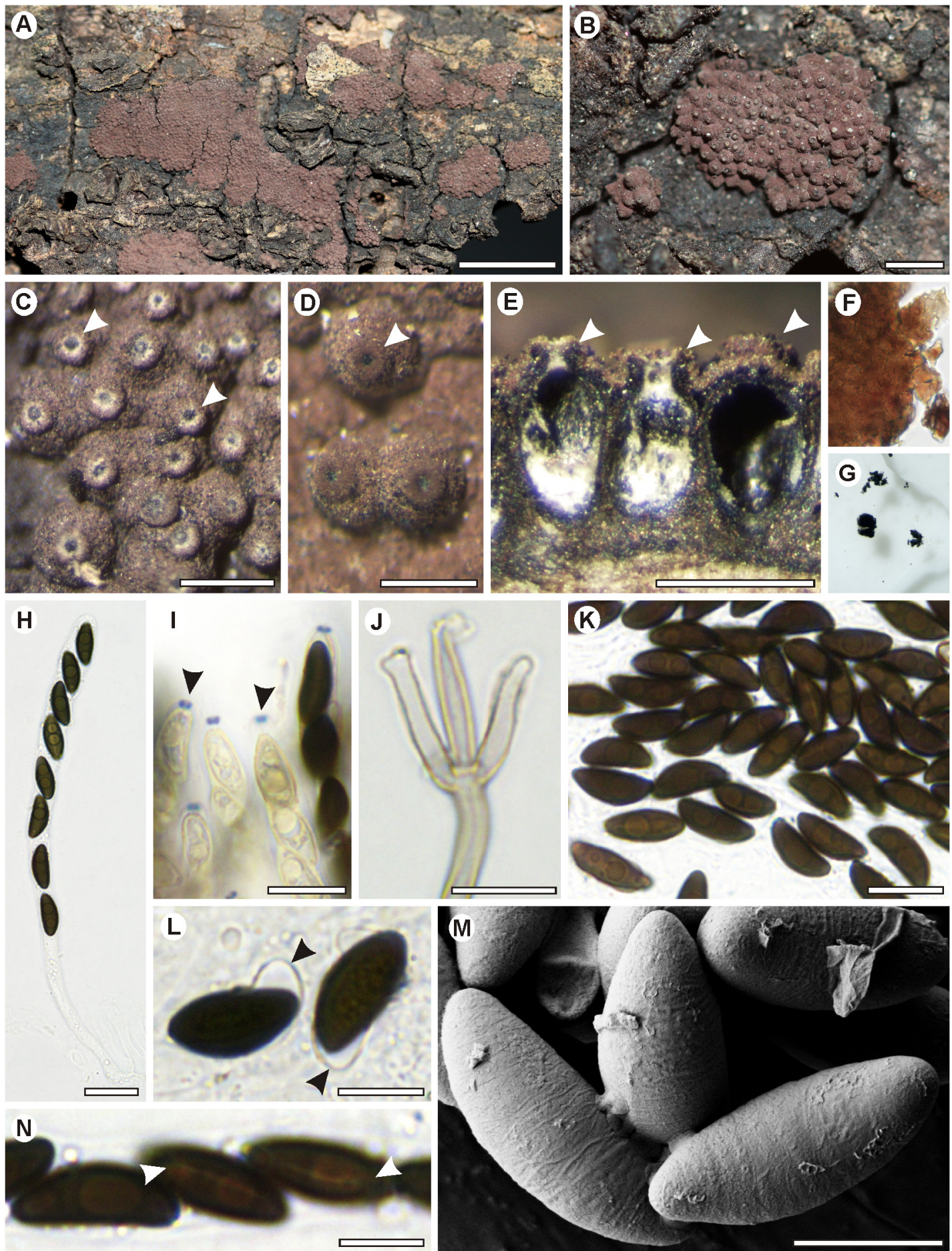

Fig. 3. Hypoxylon undulatum (Sir \& Hladki 997-LIL). A and B: stromata on bark. C and D: stromatal surface showing ostiolar discs (arrows). E: stromata in vertical section showing perithecia and ostiolar disc (arrows). F: stromatal granules in water. G: portion of stroma in $10 \% \mathrm{KOH}$. H: ascus, I: ascus in Melzer's reagent (arrows). J: branching of anamorph. K: ascospores. L: ascospores in KOH solution showing dehiscent perispore. M: ascospores view under SEM showing faintly striated perispore. $\mathrm{N}$ : ascospores with germ slit (arrows). Scale bars. A: $5 \mathrm{~mm}, \mathrm{~B}: 1 \mathrm{~mm}$. C-E: $0.3 \mathrm{~mm}, \mathrm{H}-\mathrm{K}: 10 \mu \mathrm{m}$. L-N: $5 \mu \mathrm{m}$. 


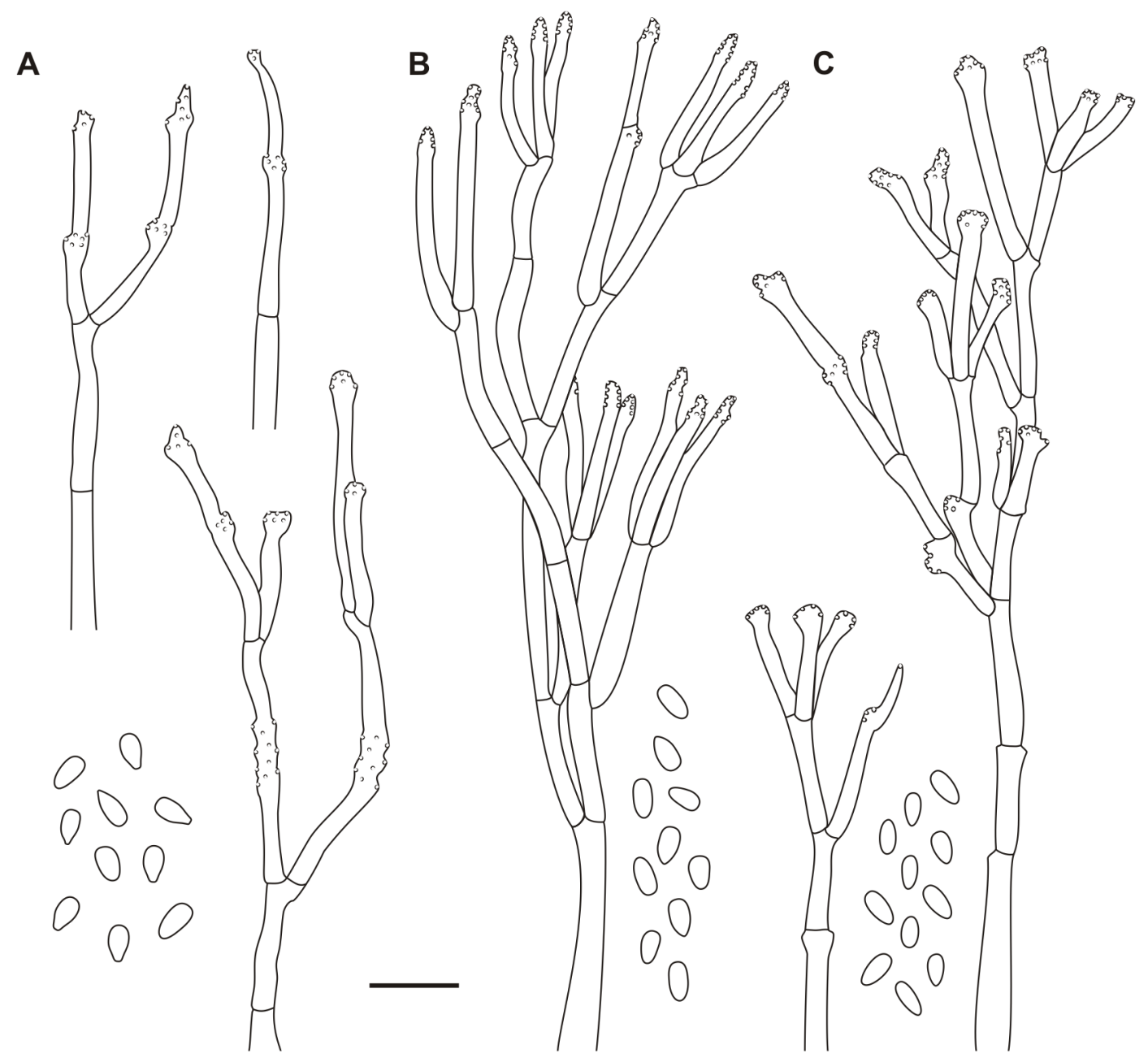

Fig. 4. Conidiophores and conidia. A: H. aeruginosum var. aeruginosum (from substrate, Sir \& Hladki 410-LIL), B: H. fendleri (from substrate, Sir \& Hladki 574-LIL), C: H. undulatum (from culture, EBS 849-LIL). Scale bar $10 \mu \mathrm{m}$.

\section{Key to species of Hypoxylon in Argentina}

1. Ascospores averaging more than $25 \mu \mathrm{m}$ in length 2

1 '. Ascospores averaging less than $25 \mu \mathrm{m}$ in length 4

2. Extractable pigments isabelline, ascospores subglobose, ellipsoid to pyriform, $28-41.5 \times 17-22$ $\mu \mathrm{m}$. H. megalosporum

2'. Without apparent pigments or with dilute vinaceous grey or brown vinaceous pigments, ascospores ellipsoid

3. Perithecia obovoid 0.5-0.7 mm diam.; ascospores 29.9-48.2 $\times 16-29 \mu \mathrm{m}$ H. umbilicatum 3'. Perithecia spherical, 1-1.4 mm diam.; ascospores 27.5-33 $\times 15.5-21 \mu \mathrm{m}$ H. chionostomum

4. Stromatal surface color blue H. aeruginosum var. aeruginosum 
4'. Stromatal surface color other than above

5. $\mathrm{KOH}$-extractable pigments dark livid, vinaceous purple or without apparent pigments .............. 6

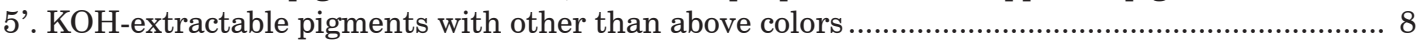

6. Stromatal surface chestnut or sepia, $\mathrm{KOH}$-extractable pigments dark livid, ascospores 7.9-14.5 $\times 5-7 \mu \mathrm{m}$ H. lividipigmentum

6'. Stromatal surface purplish gray or vinaceous gray, $\mathrm{KOH}$-extractable pigments livid purple or absent, ascospores less than $11 \mu \mathrm{m}$ long....

7. Ascospores with straight germ slit at the center of a dotted band, perispore dehiscent, smooth under SEM; conidiophores with nodulisporium-like branching patterns H. carneum

7'. Ascospores with straight germ slit not at the center of a dotted band, perispore dehiscent with inconspicuous striated ornamentation under light microscope, very conspicuous striated under SEM, conidiophores with virgariella-like branching patterns H. lilloi

8. Ascospores nearly equilateral to slightly inequilateral, with germ slit on flattened side, perispore indehiscent in $10 \% \mathrm{KOH}$

8'. Ascospores conspicuously inequilateral, with germ slit on convex side, perispore dehiscent in $10 \% \mathrm{KOH}$

9. Stromata pulvinate with inconspicuous to conspicuous perithecial mounds, surface sulfur yellow, $\mathrm{KOH}$-extractable pigments red livid or vinaceous livid, ascospores 11-12 $\mathrm{mm} \times 5-6 \mu \mathrm{m} \ldots .$.

H. kermesii

9'. Stromata effused-pulvinate, plane or with inconspicuous perithecial mounds, surface dark vinaceous to brown vinaceous, $\mathrm{KOH}$-extractable pigments dull green or dark green

10. Ascospores 9-11 $\times 4-5 \mu \mathrm{m}$

H. investiens var. magnisporum

$10^{\prime}$. Ascospores 7-10 × 3.3-4.5 $\mu \mathrm{m}$ H. investiens var. investiens

11'. Stromata hemispherical, pulvinate, effused, effused pulvinate; plane or with inconspicuous to conspicuous perithecial mounds

11'. Stromata glomerate to effused-pulvinate with conspicuous to very conspicuous perithecial mounds, sometimes with the tendency to be perithecioid (approaching rosellinioid)

12. Extractable pigments orange, scarlet or rust

12 '. Extractable pigments olivaceous, gray olivaceous, greenish olivaceous, dull green, dark green, amber, isabelline or fawn

13. Stromata with dull-colored granules, yellowish brown or brown ............................................... 14

13 '. Stromata with bright-colored granules, orange or orange red

14. Ascospores 8-12 $\times 4-5.5 \mu \mathrm{m}$

H. rubiginosum var. rubiginosum

14'. Ascospores 7.5-9 × 3.5-5 $\mu \mathrm{m}$

H. rubiginosum var. microsporum

15. Ascospores greater than $15 \mu \mathrm{m}$ long

15'. Ascospores less than $15 \mu \mathrm{m}$ long

16. Perithecia long tubular, more than $1.5 \mathrm{~mm}$ high, ascospores $15.1-23.5 \times 6.0-8.9 \mu \mathrm{m}$, with smooth perispore, straight germ slit; conidiophores with periconiella-like branching patterns.

H. haematostroma

16'. Perithecia spherical, ovoid, obovoid or tubular, less than $1.5 \mathrm{~mm}$ high, ascospores 14.5-17 $\times 6.5-7 \mu \mathrm{m}$ with faintly striated to striated perispore, straight or slightly sigmoid germ slit; conidiophores with virgariella-like branching patterns.

H. crocopeplum

17. Ascospores less than $12 \mu \mathrm{m}$ long and $5.5 \mu \mathrm{m}$ wide

17'. Ascospores greater than $12 \mu \mathrm{m}$ long and $5.5 \mu \mathrm{m}$ wide

18. Stromatal surface brown vinaceous, dark vinaceous, dark brick, or sepia, ascospores $8-12 \times$ 4-5.5 $\mu \mathrm{m}$, sigmoid germ slit, conidia 4-6 $\times 2.5-4 \mu \mathrm{m}$ H. fendleri

18'. Stromatal surface umber, sepia, rust, sienna, dark brick, or bay; ascospores 7-11 $\times 3.5-5.5 \mu \mathrm{m}$, straight to slightly sigmoid germ slit, conidia $3-4.5 \times 1.5-2 \mu \mathrm{m}$ H. subgilvum 
19. Ascospores 10.7-15.0 $\times$ 4.9-7.7 $\mu \mathrm{m}$, sigmoid germ slit; conidiophores with virgariella-like branching patterns, conidia $4.5-5 \times 2-2.5 \mu \mathrm{m}$

H. spegazzinianum

19'. Ascospores 9.5-14.3 $\times$ 4.7-6.5 $\mu \mathrm{m}$, straight germ slit; conidiophores with nodulisporium-like branching patterns, conidia $5-8 \times 3-4 \mu \mathrm{m}$ H. calileguense

20. Ostioles umbilicate with white tissue surrounding the ostioles; conidiophores with virgariellalike branching patterns. H. perforatum

$20^{\prime}$. Ostioles umbilicate without white tissue surrounding the ostioles; conidiophores with nodulisporium-like branching patterns 21

21. Stromata pulvinate to effused-pulvinate (rare glomerate) with inconspicuous to conspicuous perithecial mounds, surface sepia, chestnut, perithecia spherical 0.2-0.5 mm diam.

H. subrutilum

21 '. Stromata effused-pulvinate, plane or with inconspicuous perithecial mounds, surface brown vinaceous or dark vinaceous, perithecia obovoid to tubular $0.2-0.3 \mathrm{~mm}$ diam.

22. Stromatal granules dull olivaceous yellow; ascospores 9.7-13.0 $\times$ 4.0-5.7 $\mu \mathrm{m}$, with straight germ slit spore-length ..................................................................................... H. griseobrunneum

22 '. Stromatal granules dull reddish brown or blackish; ascospores with straight to slightly sigmoid germ slit spore-length

23. Ascospores 10-12.5 × 4.2-5.6 $\mu \mathrm{m}$, conidia 5-7 $\times 3-4 \mu \mathrm{m}$

H. anthochroum

23'. Ascospores 12.3-13.5 × 5-6 $\mu \mathrm{m}$, conidia 3-4.5 × 1.5-2 $\mu \mathrm{m}$. H. duranii

24. Ostioles slightly higher than the stromatal surface or with small papilla, ascospores $11-17 \times 4-6$ $\mu \mathrm{m}$ with sigmoid germ slit; conidiophores with nodulisporium-like branching patterns.

H. lenormandii

24 '. Ostioles umbilicate most often opening at the centre of a raised disc, ascospores with straight or straight to slightly sigmoid germ slit, conidiophores with virgariella-like or nodulisporiumlike branching patterns.

25. Without apparent extractable pigments; ascospores shorter than $12 \mu \mathrm{m}$ and narrower than 6 $\mu \mathrm{m}$; conidiophores with nodulisporium-like and virgariella-like branching patterns

25 '. Extractable pigments amber, orange or pure yellow; ascospores longer than $13 \mu \mathrm{m}$ and wider than $6 \mu \mathrm{m}$; conidiophores with virgariella-like branching patterns .....

26. Apical apparatus bluing in Melzer's iodine reagent, discoid, ascospores 13.9-21 × 6.8-10.2 $\mu \mathrm{m}$, conidia 5-6.5(-7) $\times 2-3 \mu \mathrm{m}$ H. flavoargillaceum 26 '. Apical apparatus highly reduced or lacking, not bluing in Melzer's iodine reagent, ascospores $14.5-15.5 \times 6.5-8 \mu \mathrm{m}$, conidia 4.5-5.5 $\times 3-3.5 \mu \mathrm{m}$ H. notatum

KOH-extractable pigments (Ju \& Rogers, 1996). The cultures obtained from Argentine material show the same features described for the ex-type culture of this species.

Medina et al. (2017) reported one specimen for Argentina found on Ocotea porphyria (Griseb.) van der Werff (Lauraceae) as H. cf. undulatum. It differs principally from the specimens here described by having orange extractable pigments.

\section{ACKNOWLEDGMENTS}

The authors express their appreciation to the authorities of Consejo Nacional de Investigaciones Científicas y Técnicas (CONICET) and the Fundación Miguel Lillo (FML) for constant support. Futhermore, we thank the Administración de Parques Nacionales of Argentina, Ministerio de Medio Ambiente of Salta Province and the Dirección Provincial de Biodiversidad of Jujuy Province for authorization of collection. We gratefully acknowledge support from the curators of international herbaria, who provided important specimens for the present study. EBS is thankful to Jorge Salas from the FML for logistical assistance.

\section{REFERENCES}

Catania, M.V. \& A.I. Romero 2010. Micromicetes asociados a la corteza y madera de Podocarpus parlatorei (Podocarpaceae) en la Argentina. VI. Ascomycota. Darwiniana 48(2): 123-140.

Daranagama, D.A., K.D. Hyde, E.B. Sir, K.M. Thambugala, Q. Tian, M.C. Samarakoon, E.H.C. 
McKenzie, S.C. Jayasiri, S. Tibpromma, J.D. Bhat, X.Z. Liu \& M. Stadler. 2018. Towards a natural classification and backbone tree for Graphostromataceae, Hypoxylaceae, Lopadostomataceae and Xylariaceae. Fungal Diversity 88: 1-165.

Fournier, J. \& C. Lechat. 2015. New, rarely recorded and unsettled species of Hypoxylon (Xylariaceae) from French Guiana. Ascomycete.org 7 (2): 63-96.

Fournier, J., C. Lechat \& R. Courtecuisse. 2015. The genus Hypoxylon (Xylariaceae) in Guadeloupe and Martinique (French West Indies). Ascomycete.org, 7 (5): 145-212.

Hellwig, V., Y.M. Ju, J.D. Rogers, J. Fournier \& M. Stadler. 2005. Hypomiltin, a novel azaphilone from Hypoxylon hypomiltum, and chemotypes in Hypoxylon sect. Hypoxylon as inferred from analytical HPLC profiling. Mycological Progress 4: 39-54.

Hladki, A.I. \& A.I. Romero. 2009a. Novedades para los géneros Annulohypoxylon e Hypoxylon (Ascomycota, Xylariaceae) en la República Argentina. Darwiniana 47(2): 278-288.

Hladki, A.I. \& A.I. Romero. 2009b. Taxonomic and nomenclatural aspects of Hypoxylon taxa from southern South America proposed by Spegazzini. Mycologia 101(5): 733-744.

Hladki, A.I. 2007. La familia Xylariaceae (orden Xylariales), en la provincia de Tucumán. Tesis doctoral. Fac. Ciencias Naturales e IML. UNT.

Index Fungorum-Authors of Fungal Names, 2018. Index Fungorum-Authors of Fungal Names. [consultated 10 October 2018]. http://www.indexfungorum.org/names/names.asp

Ju, Y.M. \& J.D. Rogers. 1996. A revision of the genus Hypoxylon. Mycologia memoir $\mathrm{N}^{\circ}$ 20. APS Press, St. Paul, MN 365.

Kuhnert, E., J. Fournier, D. Peršoh, J.J.D. Luangsa-ard \& M. Stadler. 2014a. New Hypoxylon species from Martinique and new evidence on the molecular phylogeny of Hypoxylon based on ITS rDNA and $\beta$ - tubulin data. Fungal Diversity 64: 181-203.

Kuhnert, E., S. Heitkämper, J. Fournier, F. Surup, M. Stadler. 2014b. Hypoxyvermelhotins A-C, new pigments from Hypoxylon lechatii sp. nov. Fungal Biology 118: 242-252.

Kuhnert, E.; E.B. Sir, C. Lambert, K.D. Hyde, A.I. Hladki, A.I. Romero, M. Rohde \& M. Stadler. 2017. Phylogenetic and chemotaxonomic resolution of the genus Annulohypoxylon (Xylariaceae) including four new species. Fungal Diversity 85: 1-43.

Kuhnert, E., F. Surup, E.B. Sir, C. Lambert, K.D. Hyde, A.I. Hladki, A.I. Romero \& M. Stadler. 2015. Lenormandins A-G, new azaphilones from Hypoxylon lenormandii and Hypoxylon jaklitschii sp. nov., recognised by chemotaxonomic data. Fungal Diversity 71: 165-184.

Læssøe, T., P. Srikitikulchai, J. Fournier, B. Köpcke \& M. Stadler. 2010. Lepraric acid derivatives as chemotaxonomic markers in Hypoxylon aeruginosum, Chlorostroma subcubisporum and C. cyaninum sp. nov. Fungal Biology, 114 (5-6): 481-489.

Medina, P.V., E.B. Sir \& A.I. Hladki. 2017. Primeras citas del género Hypoxylon (Ascomycota, Hypoxylaceae) sobre Ocotea porphyria (Lauraceae). Lilloa 54 (2):
202-209.

Rayner, R.W. 1970. A mycological colour chart. Commonwealth Mycological Institute, Kew and British Mycological Society.

Sir, E.B. \& A.I. Hladki. 2014. Nuevos reportes del género Rosellinia (Xylariaceae, Ascomycota) en los sectores norte y centro de Las Yungas de la Argentina. Lilloa 51: 97-107.

Sir, E.B., A.I. Hladki, M.F. Parrado \& A.I. Romero. 2012a. Biodiversity of Xylariaceae (Ascomycota) and their hosts in protected areas from Tucumán (Argentina). Kurtziana 37: 35-48.

Sir, E.B., A.I. Romero \& A.I. Hladki. 2015. A new species and a new record of Anthostomella (XylariaceaeAscomycota) on leaf-litter of Alnus acuminata (Betulaceae) from Argentina. Mycotaxon 130: 721729.

Sir, E.B., C. Lambert, L. Wendt, A.I. Hladki, A.I. Romero \& M. Stadler. 2016a. A new species of Daldinia (Xylariaceae) from the Argentine subtropical montane forest. Mycosphere 7: 1378-1388.

Sir, E.B., E. Kuhnert, A.I. Hladki \& A.I. Romero. 2018. Annulohypoxylon (Hypoxylaceae) species from Argentina. Darwiniana, nueva serie 6(1): 68-83.

Sir, E.B., E. Kuhnert, C. Lambert, A.I. Hladki, A.I. Romero \& M. Stadler. 2016b. New species and reports of Hypoxylon from Argentina recognized by a polyphasic approach. Mycological Progress 15: $1-42$.

Sir, E.B., T.C. Perera, A.I. Romero \& A.I. Hladki. 2012b. Provisional dichotomic keys for the genera and species of Xylariaceae (Ascomycota) from Tucumán, Argentina. Lilloa 49: 126-134.

Sir, E.B., T.C. Perera, A.I. Romero \& A.I. Hladki. 2012c. Novedades para el género Rosellinia (AscomycotaXylariaceae) en el Noroeste de la República Argentina. Boletín de la Sociedad Argentina de Botánica. 47: 311-321.

Sir, E.B., T.C. Perera, A.I. Romero \& A.I. Hladki. 2013. Stilbohypoxylon quisquiliarum (Ascomycota, Xylariaceae), nueva cita para la Argentina. Darwiniana, nueva serie 1: 289-294.

Stadler, M., J. Fournier, E. Beltrán-Tejera \& A. Granmo. 2008. The"red Hypoxylons" of the northern hemisphere. North American Fungi 3: 73-125.

Thiers, B. [permanently updated, consulted 2018] Index Herbariorum: a global directory of public herbaria and associated staff. New York Botanical Garden's Virtual Herbarium, http://sweetgum.nybg.org/ih

Wendt, L., E.B. Sir, E. Kuhnert, S. Heitkämper, C. Lambert, A.I. Hladki, A.I. Romero, J.J. LuangsaArd, P. Srikitikulchai, D. Peršoh \& M. Stadler. 2018. Resurrection and emendation of the Hypoxylaceae, recognized from a multigene phylogeny of the Xylariales. Mycological Progress: 17:115-154.

Doi: 10.22179/REVMACN.20.590

Recibido: 28-VI-2018 Aceptado: 16-X-2018 